\title{
Forensic Soil Analysis Using the Electron Microprobe: The Markice-Bowling Case
}

Steven J. Singletary ${ }^{1}$ and Heather D. Hanna ${ }^{2}$

1. Science Department, Robeson Community College, Lumberton, NC, USA.

2. Department of Geological Sciences, University of North Carolina at Chapel Hill, Chapel Hill, NC, USA.

Electron probe micro-analysis (EPMA) is a standard analytical tool for geologists, metallurgists and material scientists. EPMA can provide very high spatial resolution, quantitative chemical analyses of a wide variety of materials. Used predominantly for rock and mineral analyses by geologists, the electron probe is gaining traction as an invaluable tool to measure metal compositions, degradation of electrical components and in some special cases, biological samples. In this work, we present a case where EPMA analysis was used in the forensic analysis of soil.

Soil is formally defined as a mixture of rock and sediment that has been modified by physical and chemical interaction with organic material and rainwater over a period of time [1]. Soil formation is strongly related to local geology such that a mass of soil will consist of varying proportions of minerals that are usually derived from the underlying geologic unit, mixed with organic matter. Due to geological variations, the individual components themselves will also vary in composition across several different chemical systems such as major elements, minor elements, trace elements, and isotopes. The combinations of all these variations mean that the mineral components of a soil sample from any given location may have a distinctive composition that can be used to differentiate it from soil in other locations. By establishing the compositional differences between soil from various locations, it then becomes possible to determine if soil in trace evidence, such as on a suspect's shoe, is consistent with the crime scene and not from other alibi locations. In addition to natural variations in soil composition, materials may be brought into an area for the purposes of construction or erosion abatement and will have different mineral compositions from those of the native soil. These natural and induced variations should provide ample differences that can be exploited to identify a location through careful analysis of the soil mineral composition. Key to this study was the ability to perform precise, quantitative chemical analyses on very small sample quantities.

The case, $N C v$. Jordan Peterson, examined forensic soil evidence collected from a pair of shoes and sweat pants worn by the suspect and from two dental stone casts of foot prints from the crime scene (referred to in the Forensic report and here after as samples 6A and 7A; [2,3]). All samples contained white mica. The suspect declined to provide potential locations for exclusion samples. To demonstrate the variability of mica compositions in a larger context, material containing mica representative of local Piedmont rock types was collected for inclusion in the chemical analysis. Three "Index Sample" sites were selected and sampled based on rock type and ease of access.

Two different procedures were used to mount samples for EPMA; polished acrylic mounts and double sticky-sided carbon tape adhered to a microscope slide. Polished acrylic mounts were prepared for the index samples due to the abundance of mica. The limited quantity of mica grains in the forensic samples (shoes, sweatpants, 6A, and 7A) necessitated the second method to minimize potential loss of sample during the mounting procedure. Sand-sized mica grains were hand-picked from the shoes and sweatpants under a binocular microscope and placed on separate strips of double-sticky-sided carbon tape adhered to a glass slide. Quantitative data on mica grains were collected using WDS mode on the JEOL JXA-8530F 
Hyperprobe at Fayetteville State University. Ten replicated data points were collected and averaged for each of ten mica flakes for each sample set - shoes, sweatpants, and samples 6A and 7A. Figure 1 shows a typical bivariate plot of elemental composition data from the forensic and index samples. When plotted on bivariate plots, the major elemental oxide compositions between mica collected from the suspect's sweatpants and shoes are consistent with micas collected at the crime scene (evidence sample 6A and 7A). The compositional fields for micas from the forensic samples show significant overlap indicating that they are chemically consistent with each other. Chemical compositions of micas from the forensic samples were then compared to compositions of micas collected from other locations in the NC Piedmont (Triangle Quarry, Falls Lake, and Knightdale Quarry). The plot of MgO vs. SiO2 (Figure 1) shows the Falls Lake micas plot on trend with the compositional fields of micas from the shoes, sweatpants and the crime scene. In contrast, Triangle Quarry and Knightdale Quarry micas fall off the trend and plot in compositional fields that do not overlap with the compositional fields of micas from the forensic samples. Though the crime scene and the Knightdale Quarry are in the same unit, they still have important compositional differences, mainly the presence of two groups of mica at the crime scene but only one in the Knightdale quarry. The crime scene is located near the geologic boundary of the rock unit and may contain micas from the adjacent unit. The presence of both units in the area near the crime scene could account for the two populations of mica in the crime scene samples, while the Knightdale Quarry, located away from the boundary, has only one population. Collectively, the compositional data indicate that micas collected from the sweatpants and shoes are consistent with micas collected from the crime scene, but are not consistent with micas collected from other locations around the North Carolina Piedmont. Mr. Peterson was found guilty of first degree murder on March 26, 2010 and sentenced to life in prison. Testimony regarding the mica analysis played an important role in the jury's decision suggesting the usefulness of mineral grain compositional analysis in forensic cases. This case set a legal precedent in Wake County as the first time this type of analysis had been used in court [2].

\section{References:}

[1] S. Marshak, "Earth, Portrait of a Planet" (2008) 832 p.

[2] H. Hanna, et al, Geological Society of America, (2010) p. 66.

[3] H. Hanna, et al, Case Report \# P08-141760.

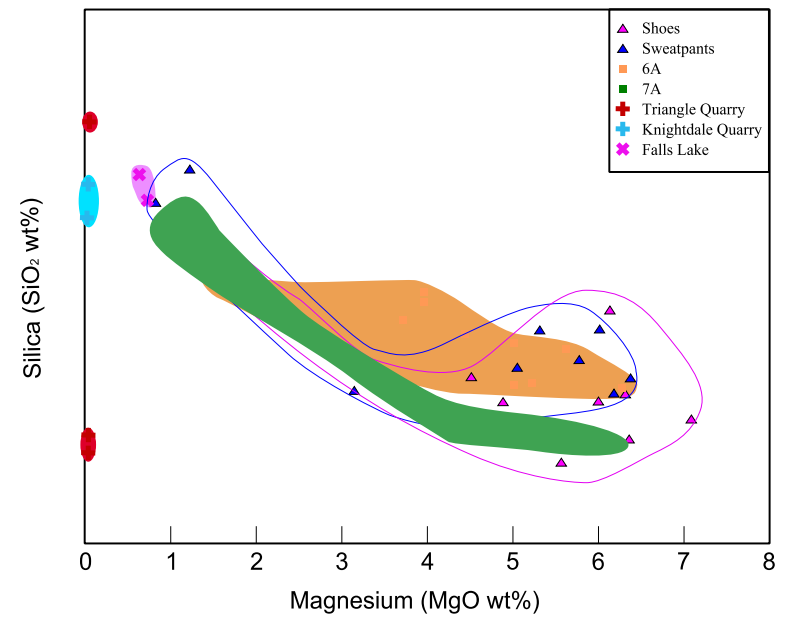

Figure 1. $\mathrm{MgO}$ vs $\mathrm{SiO}_{2}$ of index samples, crime scene samples and soil recovered from shoes and sweatpants worn by the suspect. 